\title{
ECOS GLAUBERIANOS no cinema sul-africano
}

João Evangelista do Nascimento Neto (UNEB)

$1^{\circ}$ Acorde: prólogo, sons, trilhas

Ao subir em um lugar alto e, de lá, gritar uma sentença, impostando a voz, o som irá se propagar, sendo levado pelo ar, gerado o efeito conhecido como eco. O eco, essa resposta ao que foi dito, toma espaços diversos, quebrando a barreira física de quem pronunciou, pois ele alcança lugares e alturas onde o emitente não poderia chegar.

$\mathrm{O}$ som, pois, reverbera em espaços os mais diversos e em tempos distintos. Um ruído emitido há certo tempo passado pode, ainda, ser ouvido hoje, na eminência de ser compreendido. O som faz parte do cotidiano humano e, por isso mesmo, habita os seus mais diversos afazeres, seja no âmbito cotidiano, seja nas expressôes de arte que produz.

No cinema não é diferente, mesmo no cinema mudo, o som representava a narrativa, através dos músicos que se apresentavam durante a exibição da película. Com o advento do cinema falado, as trilhas sonoras ganham cada vez mais espaço, sendo, inclusive, passíveis de premiação. $\mathrm{O}$ som, no cinema, acompanha toda a narrativa, de forma impetuosa nos momentos mais dramáticos, de maneira mais dinâmica na comicidade ou até mesmo se calando, já que a trilha do silêncio também fala aos espectadores.

É, portanto, pelo viés do som que este trabalho se configura. Por meio da música do filme Deus e o Diabo na Terra do Sol, do cineasta baiano Glauber Rocha, ecoando pelo tempo, que se chega à partitura do filme Infância Roubada, do sul-africano Gavin Hood. Duas obras fílmicas de tempos distintos, realizados em continentes diferentes, 
mas que dialogam através das notas musicais e da intenção dos criadores de suas trilhas em contar, também, o enredo dos filmes por meio das suas cançôes.

\section{2o Acorde: o cinema novo, a música, a linguagem}

\section{Segundo Berchmans:}

Parece haver um consenso entre a maioria dos compositores no sentido de que a música deve servir ao filme. Ela deve auxiliar a narrativa, seus personagens, seu ritmo, suas texturas, sua linguagem, seus requisitos dramáticos. (2006, p. 20).

Em Deus e o Diabo na Terra do Sol, a música é utilizada como meio de complementação das cenas, acentuando seu caráter de dramaticidade e fixando sua agilidade.

Grande expoente do Cinema Novo, Glauber Rocha contribui para a criação e a expansão de uma nova linguagem cinematográfica em um país subdesenvolvido que cansara de utilizar a fórmula hollywoodiana de fazer filmes. Com os grandes estúdios falidos e o advento da televisão, um grupo de empreendedores, influenciado pela Nouvelle Vague e pelo Neo-Realismo italiano, rejeita a exaustiva fórmula de copiar os filmes americanos com seus planos perfeitos e bem acabados, com o tradicional posicionamento de câmera para, enfim, garantir vida aos filmes, rejeitando a rigidez de enquadramento, bem como a opçáo por uma câmera móvel, partícipe da ação.

O enredo dos filmes no Cinema Novo deixa de ser linear, pois mais importante que a ação executada é a reflexão que ela provoca no espectador. Há uma forte discussão social e política, indissociáveis, sobretudo, nos países subdesenvolvidos, como o Brasil. Daí a utilização da estética da fome, conforme defendida pelo próprio Glauber Rocha, seguida da estética da violência.

O tratamento dado às trilhas de filme também se modifica no Cinema Novo. Mesmo que muitos críticos afirmem que há certo descaso nas trilhas dos filmes desse período, em Deus e o Diabo na terra do sol, as canções funcionam como complementação de ideias e diálogos. A linguagem fílmica funciona, também, pelas cançóes originais, como cordéis cantados, compostas para a película.

\section{3 o Acorde: Glauber, Deus, o Diabo e o Povo}

A década de 60 do século XX é o momento de questionar a falta de ação política nas periferias do país, nos recônditos abandonados pelo poder público, gerando o surgimento de um poder paralelo. A violência é a materialização da fome, a necessidade de 
sobrevivência. A música em Deus e o Diabo na Terra do Sol, assinada por Glauber Rocha (letrista), Sérgio Ricardo (composição e interpretação) e Heitor Villa-Lobos, representa a angústia e o lamento da populaçáo desvalida, sem perspectivas. Segundo Rocha:

[...] Aqui reside a trágica originalidade do 'cinema novo' diante do cinema mundial: nossa originalidade é a nossa fome, que é também a nossa maior miséria, na medida em que é sentida, mas não compreendida. [...] O comportamento normal de um faminto éa violência, mas a violência de um faminto não é primitivismo; a estética da violência antes de ser primitiva é revolucionária, e eis o momento em que o colonizador apercebe-se do colonizado. (apud VALENTINETTI, 2002, p. 41).

Evidenciar a fome e a violência dos pobres é retirar o véu que cobre as demais classes sociais e que impede de ver a situação de parte da população brasileira. Não há mais como fingir-se de cego. Exposto na película, o sofrimento e a miséria geram perplexidade e atenção, para, em seguida, poder originar uma reaçáo intelectual, primeiramente, e depois uma ação concreta. Eis a intenção da obra cinemanovista, abraçada por vários cineastas ao longo dos anos.

Em Deus e o Diabo, o cenário rural, mais especificamente o sertáo nordestino, é o ambiente escolhido para evidenciar a luta pela sobrevivência. Do espaço agrário, combalido pela seca, surgem os moradores, oprimidos entre o fanatismo religioso e o poder exercido pelo cangaço. A música que introduz a película, Abertura, didaticamente apresenta o enredo:

Vou contar uma estória

$\mathrm{Na}$ verdade e imaginação

Abram bem os seus olhos

Pra enxergar com atenção

É coisa de Deus e o Diabo

Lá nos confins do sertão.

(ROCHA, 1964)

É ficcional o enredo, a canção deixa evidente, mas o fato de o eu-lírico pedir que o ouvinte/espectador atente para o que verá, explicita a verossimilhança da narrativa com a realidade vivida no espaço retratado, o sertão. Música e imagem, pois, para o cantador, fundem-se. Pelos ouvidos e olhos, a música ganha materialidade e é sorvida pelo espectador numa atitude sinestésica. Compreender o que se passa nos 'confins do sertão' exige todos os sentidos. A verdade imaginativa, citada na música, é por onde corre o sangue que pulsa por transformação da realidade vigente. 
As composições de Heitor Villa-Lobos aparecem sempre para dar maior dramaticidade às cenas. É assim quando Manuel mata o Coronel Moraes ao som de Dança das bachianas brasileiras $n^{\circ} 2$, ou quando a voz de Sebastião, o beato negro, é enfatizada pelo Magnificat aleluia, ou ainda a cena de amor entre Corisco e Rosa dá-se com Cantilena, ária das Bachianas brasileiras no 5.

Alternadamente, a música clássica dialoga com o cancioneiro popular nordestino. O som da orquestra e as vozes do coral cedem espaço à cantiga do narrador do sertáo e ao coro popular.

O cego é o cantador/contador. Embora não participe, é o fio condutor da narrativa. O cego que habita as feiras livres, que dá voz aos cordéis, que cria e reproduz repentes é o narrador oficial. Para contar as vicissitudes sertanejas, Glauber Rocha escolhe um sertanejo, deficiente, alijado da sociedade. Ele é o detentor da sabedoria prática. Pela voz do cego cantador, o espectador enxerga a realidade diária.

No sertão, há que se sobrevier a qualquer custo, seja apelando para o discurso bíblico e crendo que o sertão transformar-se-á num mar e, com ele, a mutação de terras improdutivas em férteis, ou entrando em um dos grupos de revoltosos, como meio de demonstrar a insatisfação pela não ação política oficial, criando um sistema próprio de governo, cujas regras são estabelecidas a partir de um código próprio de conduta, cuja quebra pode gerar a morte.

Glauber Rocha, pois, apresenta, em seu filme, a terceira via, o rompimento com o messianismo que aliena e com o cangaço que extermina:

Deus e o Diabo na terra do sol dramatiza os fenômenos do messianismo e do cangaço e o tema da revoluçáo [...] Isso significa que no filme os dois fenômenos [...] entram em cena para serem descartados como soluçôes "nefastas" e "inócuas" aos problemas sociais da estrutura coronelista. Em seu lugar, o filme oferece [...] uma terceira saída: a saída revolucionária. (FARIAS, 2010, p. 158).

A revolução é o meio para desequilibrar o jogo de poder instituído, o terceiro elemento para gerar a desestruturação de um status quo opressor. Antônio das Mortes configura-se, portanto, o gerador da insurreição popular. Mas não se faz uma revolução sem ferocidade, e esta se torna necessária para que venha a transformação. A película já se apresenta ao espectador como uma violência e o choque ao assistir a tal narrativa fílmica é mister a fim de cooptar o espectador a uma análise da condição social do país, da América Latina e dos demais países colonizados, permitindo que esse espectador saia de sua condição de passividade.

Para criar um ambiente de inquietude, a música de Deus e o Diabo na terra do sol precisa coadunar com o enredo. A escolha pelo cordel representa a cultura popular alija- 
da da sociedade. Com versos que se repetem, as cançôes da trilha sonora são usadas para fixar na mente do espectador as ideias disseminadas ao longo da narrativa. Através das cançôes, os personagens são apresentados e a narrativa é complementada. Pela música, o espectador fica cara a cara com Antônio das Mortes, o revolucionário, a terceira via:

Jurando em dez igrejas

Sem santo padroeiro

Antônio das Mortes

Matador de cangaceiro

Matador, matador

Matador de cangaceiro!

(ROCHA, 1964).

A palavra 'matador' é repetida quatro vezes na canção "Antônio das Mortes" e 'cangaceiro' aparece outras duas. As duas últimas estrofes, como em um eco, são incessantemente reproduzidas. Tal repetição, comum no cancioneiro popular, geralmente de autoria desconhecida, aqui reforça a importância do personagem na obra: a de trazer a mudança para o sertấo, para o país. Sua função é apresentar a morte para um sistema estabelecido.

A despeito da morte física na obra glauberiana, há a denúncia de outra há muito ocorrida: os sertanejos são invisíveis sociais. $\mathrm{O}$ círculo vicioso religiáo-cangaço, que a maioria dos nordestinos não consegue romper, serve para

[...] demonstrar a inutilidade das tentativas anarcóides como a fuga "in alto", isto é, para misticismo e/ou a violência pura, como forma de resolver um estado de crise perene. A tomada de consciência seria a única solução positiva. (VALENTINETTI, 2002, p. 59).

Daí a necessidade de analisar a linguagem enquanto "o principal mecanismo pelo qual a cultura produz e reproduz os significados sociais." (TURNER, 1997, p. 51).

Entende-se aqui linguagem em seu âmbito mais geral, o que inclui toda a trilha sonora (soundtrack) de um filme, a saber, os diálogos, os efeitos sonoros e a música. Embora o a música original do filme (score) lide especificamente com a música composta para a película, há que se ponderar que uma análise do score, retirando-lhe do contexto fílmico, certamente, alterará o significado atribuído a ele na sequência em que foi inserido.

Na película, aliada às cançôes populares, há a música de Heitor Villa-Lobos. Esse diálogo entre o popular e o erudito confere ao filme uma permanente polifonia. Assim, Deus e o Diabo na Terra do Sol foge de um pretenso maniqueísmo muito co- 
mum no imaginário popular. A revolta popular é urgente, mas outras camadas sociais podem-se juntar a ela. Dessa forma, o próprio cineasta inclui-se na luta que legitima em seu filme.

Há, na trilha da obra glauberiana, uma continuidade entre as composiçóes populares. Quase todas em um andamento andante, que ora se aligeira (allegretto), para depois retomar seu andamento anterior. A exceção é as duas cançôes finais, que retratam o embate entre Corisco e Antônio das Mortes e a fuga de Manuel e Rosa em direção ao tão desejado mar:

\section{Perseguiçáo / Sertáo Vai Virar Mar}

Se entrega Corisco!

Eu não me entrego não!

Eu não sou passarinho

Pra viver lá na prisão

Se entrega Corisco!

Eu não me entrego não!

Náo me entrego ao tenente,

Não me entrego ao capitão,

Eu me entrego só na morte,

De parabelo na mão!

(Corisco) Mais fortes são

Os poderes do povo!

Farreia, farreia, povo,

Farreia até o sol raiar...

Mataram Corisco,

Balearam Dadá.

O sertão vai virar mar

E o mar vai virar sertão!

Tá contada a minha estória,

Verdade e imaginação.

Espero que o sinhô tenha tirado uma lição:

Que assim mal dividido

Esse mundo anda errado,

Que a terra é do homem,

Num é de Deus nem do Diabo!

(ROCHA, 1964)

Há desenho de som (sound design) nessas duas últimas cançôes: é possível ouvir a voz de Corisco em resposta aos tiros investidos contra ele. Vencido, cai exaltando a 
força popular e o povo é chamado a festejar o fim de uma era de opressão do poder paralelo e da força da religiosidade exacerbada.

Sem o Deus negro (a religiáo) e o Diabo louro (a violência), o sertanejo, o homem periférico, o pobre e todo aquele que almeja a mudanças pode correr em direçáo ao mar. Nos versos "O sertão vai virar mar, / E o mar vai virar sertão", há a afirmativa de que o mar e o sertão estão onde o ser humano está. É ele quem faz de sua vida e de seu habitat mar ou sertão, terreno árido ou fértil, espaço de opressão ou de liberdade.

Enquanto o coro em "Sertão vai virar mar" repete os versos que opóem mar e sertáo como dois projetos distintos de escolha de vida, o solista complementa a cançáo de abertura do filme acentuando o caráter de ficção e realidade da obra fílmica. Embora os versos finais pareçam ser bastante didáticos ao explicar ao espectador a liç̧áo de moral da narrativa', conclamando todos a se unirem em prol de uma sociedade igualitária, revelando um projeto comunista, onde se excetuam religiáo e classes díspares, a imagem de Manuel e Rosa correndo pelo sertáo quebra esse didatismo. O casal náo alcança o mar, só se desloca para ele. Nesse ínterim, separa-se, mostrando que nem todos chegam a essa nova visão ao mesmo tempo:

[...] a corrida náo veicula propriamente um recado didático, uma palavra de ordem definida do tipo que encontramos no final de um panfleto político [...] Nesse sentido, seu gesto, apesar de projetivo, é uma instância em plena disponibilidade. (XAVIER, 1983, p. 72).

Música e imagem não podem, portanto, ser analisadas de forma dissociada. Em Deus e o Diabo na terra do sol, elas se complementam e, juntas, narram a história de um povo sofrido para ele mesmo e para outros povos, também sofridos. Em travelling, as primeiras imagens do filme apresentam uma terra desolada, fenecida, ao som de canção do sertão, ária das Bachianas brasileiras $n^{\circ} 2$, de Villa-Lobos. Novamente em travelling, ao som de Chorus no 10, também de Villa-Lobos, a cena final evoca a vastidão do mar e, com ela, a vida vem à tona, em tom profético e esperançoso.

Assim, na película glauberiana, os acordes musicais dão o tom de vida e de morte. Falam de vida mesmo diante da sua supressáo social. Evocam a reação do homem humilde e da mulher guerreira diante do maior mal que pode assolar uma sociedade: a anulação de si mesma.

\section{$4^{\circ}$ Acorde: Tsotsi, violência, medo e transformação}

Adaptado do romance do sul-africano Athol Fugard, Tsotsi: infância roubada, o cineasta Gavin Hood também assina o roteiro de Infância Roubada, uma coprodução 
entre África do Sul e Inglaterra. Com trilha sonora de Paul Hepker e Vusi Mahlasela, a obra fílmica aborda, no cenário urbano, o cotidiano e a dura sobrevivência de uma gangue formada por adolescentes.

O cenário é Johanesburgo, África do Sul, do final do século XX. É nesse espaço que o pequeno David dá lugar a Tsotsi, cujo significado do nome remete à delinquente. Essa transformação fora necessária para permitir a sobrevivência do garoto nos subúrbios de uma grande cidade. Crescera e tornara-se o líder de um violento grupo.

A metrópole sul-africana sofre com o crescimento da violência, o número de gangues revela a falta de oportunidades para as novas geraçóes que, sem perspectivas, vê na criminalidade a única opção de sobrevivência.

O filme, então, evidencia dois mundos diferentes: de um lado, a Johanesburgo rica, dos grandes casaróes que abrigam o dinheiro, o poder e o luxo; do outro lado, os guetos da cidade, onde superabundam a miséria, a fome e o medo. Quando esses dois espaços se cruzam, gera-se o conflito de Infância Roubada. Dois personagens, um adolescente e um bebê, um pobre de nascimento, o outro gerado num ambiente de riqueza. Ambos inocentes em relação a sua origem, ambos impotentes diante da vida que se apresenta.

Tsotsi, ao roubar um carro em um bairro nobre de Johanesburgo, leva consigo, no banco traseiro, um bebê. Então, depara-se com o futuro e o passado diante de si. Nega-se a devolver a criança, pois vê nesta a tentativa de regressar ao passado, tornar-se de novo no David protegido pela mãe, com sonhos, com futuro. Uma criança cuidando de outra criança na busca de cuidar de si mesmo, dando-se uma oportunidade de vislumbrar algo mais do que o sangue de suas vítimas, do que a dor do vazio de sua alma.

A estética da violência, elucubrada por Glauber Rocha, aplica-se na narrativa criada por Hood. Aqui, também, não há como dissociar fome de selvageria. As gangues são uma criação das classes subalternizadas incompreendidas pela sociedade. São a resposta para o descaso, para o silêncio e para a omissão do Estado. O medo é a arma utilizada por esses grupos paralelos de reestabelecimento do equilíbrio de forças, e é por meio do medo que tais grupos ganham voz, imagem, são detectados, mesmo que por um breve instante e ainda que de forma repressora:

A estética da violência e da fome, iniciada por Glauber Rocha, teria [...] um vetor consequente ao apontar para as suas causas estruturais. As elites, as oligarquias, as corporaçôes multinacionais, o poder enfim, mantêm elos concretos e lógicos com a situação de exclusão na qual vive uma grande parcela da população rural e urbana. (SOUZA, 2009, p. 44). 
A sociedade oficial, impotente diante da reação violenta de 'confrarias do terror coletivo', não sabe como reagir frente a açóes inesperadas e que atentam contra uma ordem de valores instituída, arquitetada para separar, dividir.

"É preciso entender que, num contexto miserável, ser bandido quase nunca é uma opção. É, antes, uma estratégia de sobrevivência." (MORAES, 2007, p. 63). Em Infância Roubada, a estética da fome/violência cria o caos contemporâneo do 'beco sem saída'. Não há para onde correr, não há a quem recorrer. Não há segurança nas ruas, nos metrôs, dentro das casas e mansóes. $\mathrm{O}$ homem não se sente seguro, pois a insegurança e o terror nascem dentro de si mesmo e são vomitados para o mundo a sua volta. Partindo dessa realidade, a trilha sonora da película, com incontestáveis influências pop, ora afronta o espectador com cançóes de protesto, às vezes, gritadas, ora apelam para o drama, sensibilizando esse mesmo espectador, num movimento alternado de agressão/ emoção com o intuito de cooptá-lo recorrendo à razão e ao sentimento:

Criada a partir do kwaito, estilo musical surgido em Johanesburgo nos anos 90 (século $\mathrm{XX}$ ), que se constitui em uma mescla entre a música eletrônica e ritmos africanos tradicionais, cujas letras são, geralmente, declamadas ou gritadas, a trilha sonora de Infância Roubada é um conjunto de composições, como Mdlwembe e Bhambatha, em línguas indígenas da África do Sul ou mesmo em inglês, comum ao kwaito, que dividem espaço com músicas como Stolen legs (Pernas Roubadas) e as belíssimas On the tracks (Nas Pistas) e Baby hand over (Entrega do bebê), entoadas em forma de lamento, ao tempo em que convivem com a percussão sul-africana em outras cançôes e até mesmo com composiçôes com uma batida pop. (NASCIMENTO NETO, 2011, p. 10).

A trilha sonora de Infância Roubada demarca um lugar de contemporaneidade da narrativa. O hip hop ganha destaque, pois simboliza o grito de uma população marginalizada. Conhecida como música de protesto, em suas letras, há, além da denúncia das mazelas sociais, uma declaração de vingança ao sistema, muitas vezes, materializada em açôes que afrontam o aparelhamento estatal.

Ainda sobre o hip hop, há que se identificar o processo de globalização em que o filme está inserido. Surgido nas comunidades periféricas habitadas por jamaicanos, latinos e afro-americanos, na década de 70 do século XX, em South Bronx, Nova Iorque, esse gênero musical expandiu-se para as periferias de todo o mundo, tornando-se o porta-voz dessas comunidades. A película, pois, encontra-se inserida nesse contexto global de fome e de miséria e todas as ações de Tsotsi, o líder da gangue, são acompanhadas por esse estilo, bem como por composiçôes de Kwaito. 
O kwaito é outra marca de contemporaneidade observada na obra fílmica. Sua principal característica é a hibridez, já que sua origem se dá a partir da combinação de ritmos tradicionais africanos e música eletrônica. Há, pois, a união entre a tradição e a modernidade, entre o velho e o novo. A tradição, neste caso, não é esquecida, renegada, mas revitalizada com composiçôes como Sghubu sam e Mnt’omnyama.

Como nasce nas comunidades populares dos guetos da África do Sul, certamente, o kwaito não goza de prestígio social. A música para as massas é conceituada como um gênero sem importância, modismo, um rito de passagem, contudo, os ritos simbolizam, os modismos significam, os gêneros populares dialogam, mesmo que seja para registrar um curto período e uma mensagem específica. Incompreendidos, os gêneros musicais de massa trazem uma mensagem que precisa ser ouvida, analisada e respondida. Assim como o hip hop, em composiçóes como Palesa, Seven, com sua melodia quase falada, os gritos do kwaito são denúncias, pedidos, clamores.

A música é um meio de interlocução, logo, carece de resposta. O destinatário, a sociedade, emudece porque está inaudível às vozes outras que não as suas. Ela, a sociedade, só reconhece o som que sai de sua própria boca. Em Infância Roubada, a trilha pop, em vários momentos com referências diretas à marginalidade ${ }^{1}$, demarca um lugar de fala, legitimando-o.

Mesmo que os acordes musicais falem de violência, é necessário compreender o conceito tal conceito, visto que "A violência tanto pode ser exercida para a conquista e manutenção da ordem, quanto para instaurar o ato subversivo e marginal." (NOVAES, 2007 , p. 35). Se a violência se estabelece pela ação de gangues como a de Tsotsi, ela é gerada pela violência da não atuação do Estado, da não geração de empregos, da não divisão das riquezas do país de forma mais igualitária. A justiça social dá-se, pois, pelas máos dos meninos-homens, crescidos abruptamente pela necessidade da sobrevivência. Tais ações de redistribuição de renda, sempre acompanhadas pelo ritmo ágil do hip hop ou do kwaito, contribuem para a dinamização das cenas, levando o espectador, por intermédio das cançôes, a sentir-se parte integrante da narrativa.

Ao mesmo tempo em que a trilha autentica a violência do filme, certas composiçôes, como Ehlala Zola, trazem um sentimento controverso de alegria e lamento. O coro é incessantemente repetido, como uma súplica pela vida, um pedido coletivo de um gueto que acorda, como em um romance naturalista. Em Johanesburgo, um formigueiro sobe e desce os becos íngremes e sem saneamento. Por essas vielas, transitam um enxame que mais parece uma nuvem de insetos. Animalizados frente à sociedade, Tsotsi e seus companheiros vestem essa roupa feita para eles e agem segundo os papéis sociais que lhe são dados. Mas Tsotsi, diante do bebê em suas mãos, resolve despir-se das vestes 
da marginalidade, desnuda-se dos adornos de injustiçado social a fim de, novamente, inserir-se numa sociedade que o renegou.

Nesse ínterim, é preciso afirmar que as tentativas de quebra das normas sociais são um tentame para fazer parte do grupo social que o expele. Por isso, Tsotsi quer ser novamente o David, com nome próprio de origem hebraica e que significa 'aquele que é amado'. Quer deixar a alcunha de 'gângster' para ser querido, se não por todos a sua volta, pelo menos por aquele bebê de quem se propóe a ser o protetor.

A retomada de consciência da personagem é acompanhada por uma mudança na trilha sonora. Stolen legs, On the tracks e Baby handover, com um ritmo mais lento e assemelhando-se a uma dolorosa súplica, abrem espaço para o processo de humanização de Tsotsi/David. É o pranto de quem implora por uma segunda oportunidade. Ao mesmo tempo, é a lamentação por saber que nunca será aceito pela sociedade.

A violência continua a ser desvelada em todos os planos-sequência do filme. Só se transmuta de uma agressão concreta, sanguinária, por outra abstrata, mas tão cruel quanto, que é aquela que nega ao outro o direito de existir de direito, que cala a sua voz e invisibiliza-o:

A nossa posição é que esse novo cinema de violência, longe de ser apenas uma cosmética, deslancha novas formas do bizarro, afirmando o poder de uma estética de desrazão que irrompe na arte do horror. Tal estética adquire sua função pela mediação de uma realidade permeada pela obsessáo da morte e que produz seus discursos sobre a nova sociedade urbana em seus quadros aterrorizantes. (SOUZA, 2009, p. 63).

A morte não é o maior temor de Tsotsi/David. Essa ele já conhece desde a mais tenra idade: o fenecimento de seus entes queridos, de seus sonhos e desejos, a morte de suas oportunidades. O que Tsotsi teme é, indubitavelmente, viver. É para fugir da vida e de suas idiossincrasias que Tsotsi violenta o mundo que o violenta. É para negar-se à vida que ele rouba, espanca, mata. O bebê que sequestra, no entanto, traze-o de volta à vida. E de retorno a ela, ele está suscetível a sentir dor, a ser magoado, pois se despira da armadura que o protegia. Aí a derradeira violência da última cena do filme: diante da tomada de consciência de que é inapto para cuidar de uma criança, devolve-a e é preso. Humano e sensível, David continua a ser, para o restante da sociedade, o delinquente temido e que precisa ser aprisionado, novamente, na carcaça de Tsotsi.

\section{Acordo: epílogo, diálogos e perspectivas}

Deus e o Diabo na Terra do Sol apresenta uma câmera viva, ágil, que trilha com os personagens os caminhos do sertão, as veredas do messianismo e da violência, para, 
enfim, apontar em direção ao espaço fértil do mar, onde habita a dignidade humana, o respeito e a justiça social.

Infância roubada é o álbum, cujos vários retratos evidenciam as facetas da violência, da exclusão e da intolerância na periferia de uma grande metrópole, quando é preciso automatizar-se a fim de sobreviver diante da frieza das relaçóes humanas.

Deus e o Diabo na Terra do Sol é a representação de um mundo ainda agrário, baseado no coronelismo e que almeja a uma revolução de classes.

Infância roubada é a imagem de uma sociedade urbana que não conseguiu resolver as questôes de outrora, e onde as diferenças sociais só se solidificaram.

Duas obras fílmicas criadas em contextos históricos distintos, mas que dialogam: Em Infância roubada, a ideologia revolucionária da tomada de poder e da melhor distribuição de vida, defendida em Deus e o Diabo, ainda não fora alcançada. O ser humano deixou o campo (o sertão) para a aridez da cidade:

No entanto, se o terceiro-mundismo cinematográfico encontra-se em plena atividade, o terceiro-mundismo político está em crise. A "euforia terceiro-mundista” da revolucionária da década de 1960 de há muito cedeu espaço ao desencanto produzido pelo colapso do comunismo, pela frustraçáo com respeito à almejada "revolução intercontinental", pela compreensão de que os "condenados da terra" não são unanimamente a favor da revolução (e nem necessariamente aliados uns aos outros), e pelo reconhecimento de que a geopolítica internacional e o sistema econômico global obrigaram até mesmo os regimes socialistas a reconciliar-se com o capitalismo transnacional. (STAM, 2003, p. 309).

Os ecos glauberianos, no entanto, continuam a ser ouvidos na contemporaneidade. Os sons de seu pensamento materializam-se em conceitos atuais menos idealistas, mas não deixam de apontar para a restauração do homem, para o retorno da humanidade de um ser que desaprendera a ser gente perante uma sociedade baseada no poder do capital. É assim com a obra de Hood, que assinala a regeneração do personagem, protótipo da sociedade.

A trilha sonora de Deus e o Diabo na terra do sol, com suas cançôes que dialogam com o enredo, assemelhando-se ao coro do teatro grego, reforçam o ideário de o povo acercar-se de sua importância, exercendo o poder que possui. Nesta película, a música, muitas vezes, confunde-se com as falas dos personagens e com o som ambiente, garantindo a unidade de todos os elementos fílmicos. Tudo ali existe para, junto, contar uma história, a história da humanidade.

Em Infância roubada, ouvem-se os ecos proferidos em 1964, por Glauber Rocha em seu filme. Naquele, a música alça o espectador a ser copartícipe das açôes do prota- 
gonista, a sofrer com ele a dor da rejeição e a partilhar o sentimento de novamente ser gente, mesmo que seja um sentimento pessoal de humanidade não dividido com mais ninguém em cena, embora sem crer numa transformação coletiva.

Eco é ruído, é som, é música. Se o som é propagado pelo ar, e o ar viaja por todos os lugares, não há como impedir que o grito de um baiano, na década de 60 do século $\mathrm{XX}$, alcance os ouvidos de um sul-africano, na primeira década do século XXI. E um som nunca é somente a decodificação de fonemas, ou a superposição, em uma pauta, de notas que se agrupam em compassos, mas, sobretudo, é a elucubração de pensamentos, o diálogo de ideias e a socialização de sentimentos.

\section{$6^{\circ}$ Acorde: teorias, leituras e polifonias}

Uma partitura é feita de vários acordes: os acordes do filme de Glauber Rocha e da película de Gavin Hood, mas há outros sons que contribuem para a canção ganhar corpo, ter substância, os acordes teóricos. Aqui estáo todos eles, contribuintes para a reflexão deste trabalho.

\section{$\operatorname{son}$}

\section{NOTAS}

1 Termo aqui usado para referir-se a quem está à margem da sociedade.

\section{REFERÊNCIAS}

BERCHMANS, Tony. A música do filme: todo o que você precisa saber sobre a música de cinema. São Paulo: Escrituras, 2006.

DEUS e o diabo na terra do sol [filme]. Direção: Glauber Rocha. Produção: Luis Augusto Mendes. Intérpretes: Geraldo Del Rey, Yoná Magalhães, Mauricio do Valle, Othon Bastos e outros. Roteiro: Glauber Rocha, Walter Lima Jr. Rio de Janeiro: Copacabana Filmes, 1964. (115 min), son., preto e branco.]

FARIAS, Sônia Lúcia Ramalho de. O rural e o urbano nas profecias revolucionárias de Jorge Amado e Glauber Rocha. In: FARIAS, Sônia Lúcia Ramalho de. AGUIAR, Cristhiano. (Orgs.) Intérpretes ficcionais do Brasil: dialogismo, reescrituras e representaçôes identitárias. Recife: Bagaço, 2010.

FUGARD, Athol. Tsotsi: infância roubada: seguida da peça "Mestre Harold"... e os meninos; Tradução de Alvaro Hattnher, Bruno Gomide. São Paulo: Companhia das Letras, 2007.

INFÂNCIA Roubada. Direção: Gavin Hood. Produção: Peter Fudakowski. Roteiro: Gavin Hood. Intérpretes: Presley Chweneyagae, Terry Pheto, Kenneth Nkosi, Mothusi Magano e outros. [S.L.]: Industrial Development Corporation of South Africa; 1 bobina cinematográfica (94 min.), son., color., $35 \mathrm{~mm}$. 
MORAES, Ísis. Bandido Social e NeoFavela: Descolonizaçáo e Criminalidade em Cidade de Deus. In: NOVAES, Cláudio. BOTELHO, Marcos. (Orgs.) Seis passeios por Cidade de Deus. Feira de Santana: EDUEFS, 2007.

NASCIMENTO NETO, João Evangelista do. Tsotsi, diálogos sobre uma infância roubada. Anais do II Xirê das Letras, UNEB: Xique-Xique, 2010. Disponível em: www.iixiredasletrasuneb.blogspot.com. $\mathrm{br} / \mathrm{p} / \mathrm{anais} \cdot \mathrm{html}$ ?m=1. Acesso em 02/03/2014, às $15 \mathrm{~h}$.

NOVAES, Cláudio. Batismos profanos: a estética da violência contra o dragão da cosmética. In: NOVAES, Cláudio. BOTELHO, Marcos. (Orgs.) Seis passeios por Cidade de Deus. Feira de Santana: EDUEFS, 2007.

SOUZA, Lícia Soares de. Literatura e cinema: traduções intersemióticas. Salvador: EDUNEB, 2009.

STAM, Robert. Introdução à teoria do cinema. Tradução de Fernando Mascarello. Campinas, SP: Papirus, 2003.

TURNER, Graeme. Cinema como prática social. Tradução de Mauro Silva. São Paulo: Summus, 1997.

VALENTINETTI, Claudio M. Glauber Rocha, um olhar europeu. São Paulo: Instituto Lina Bo e P. M. Bardi: Prefeitura do Rio, 2002.

XAVIER, Ismail. Sertão mar: Glauber Rocha e a estética da fome. São Paulo: Brasiliense, 1983.

\section{Resumo}

A película Deus e o Diabo na terra do sol, de Glauber Rocha, dialoga, nesse estudo, com a obra fílmica Infância Roubada, do sul-africano Gavin Hood, a fim de analisar, por entre claves e tons, a influência da obra brasileira na trilha sonora do filme realizado na África do Sul. A música no filme tem, como objetivo primordial, a função de contar a história, contribuindo para que o espectador compreenda a narrativa. Em Deus e o Diabo, ela, de cunho popular, ganha notoriedade ao ser posta em diálogo com a música erudita. Em Infância Roubada, a música representa a voz e os anseios de uma população marginalizada. Desse modo, por meio do viés da estética da fome e da violência, e apropriando-se dos acordes teóricos de Berchmans (2006), Novaes (2007), Souza (2009), Stam (2003), Valentinetti (2002) e Xavier (1983), dentre outros, o cinema brasileiro baila com o sul-africano ao som de cançóes que significam e simbolizam o ser humano em convívio consigo mesmo e com seus semelhantes.

\section{Resumen}

Deus e o Diabo na terra do sol, del cineasta Glauber Rocha, dialoga, en este estudio, con la película Infância Roubada, de Gavin Hood, con el fin de examinar, entre claves y tonos, la influencia de la obra brasileña en el sonido de la película sudafricana. La música en la película tiene, como objetivo principal, la función de contar la historia, ayudando al público a comprender la trama. En Deus e o Diabo, la música, de origen popular, ha ganado notoriedad cuando se pone en diálogo con la música clásica. En Infância Roubada, la música representa la voz y preocupaciones de una población marginada. Así, por medio de la estética del hambre y la violencia, y la apropiación de le los estudios de Berchmans (2006), Novaes (2007), Souza (2009), Stam (2003), Valentinetti (2002) y Xavier (1983), entre otros, el cine brasileño baila con el sudafricano, al son de las canciones que significan y simbolizan el ser humano en comunión consigo mismo y con sus semejantes. 
NASCIMENTO NETO, João Evangelista do, Ecos glauRevista de Literatura berianos no cinema sul-africano. Légua \& Meia: Revista de literatura e diversidade cultural. Feira de Santana: UEFS, A. 14, no 7 , 2016, p 47-61.

Joáo Evangelista do Nascimento Neto é professor da área de Literatura da Universidade do Estado da Bahia (UNEB), é mestre em Literatura e Diversidade Cultural pela Universidade Estadual de Feira de Santana (UEFS) e Doutor em Letras pela Pontifícia Universidade Católica do Rio Grande do Sul (PUCRS). Coordena o grupo de pesquisa Escritas à deriva: redes literárias nas malhas da ficção em língua portuguesa e língua espanhola. E-mail: netoevangelista@ uol.com.br. 